\section{Case Reports in Neurology}

Case Rep Neurol 2021;13:9-16

DOI: 10.1159/000510847

Published online: January 8, 2021
(C) 2021 The Author(s) www.karger.com/crn

This article is licensed under the Creative Commons Attribution-NonCommercial 4.0 International License (CC BY-NC) (http://www.karger.com/Services/OpenAccessLicense). Usage and distribution for commercial purposes requires written permission.

\title{
Unusual Presentation in Infratentorial Superficial Siderosis: Acute Intracranial Hypertension
}

\author{
Maria Sheila Guimarães Rocha ${ }^{a, b}$ Hugo Salomão Grangeiro Mirôa \\ Gregori Manfroi $^{a} \quad$ Arthur de Medeiros Dias $^{a} \quad$ Raphaella Cardoso $^{a}$ \\ Sonia Maria Dozzi Bruckia, $c$ \\ aDepartment of Neurology, Hospital Santa Marcelina, São Paulo, Brazil; 'bepartment of \\ Internal Medicine, Faculdade Santa Marcelina, São Paulo, Brazil; 'Department of \\ Neurology, University of São Paulo, São Paulo, Brazil
}

\section{Keywords}

Superficial siderosis · Neurodegeneration · Intracranial hypertension · Ferritin · Neurosensorial deafness

\section{Abstract}

Superficial siderosis (SS) of the nervous system is a rare acquired condition related to hemosiderin deposits in subpial layers of the brain, brainstem, cerebellum, cranial nerves, and spinal cord, leading to brain iron-mediated neurodegeneration. The cardinal neurological features are slowly progressive hearing loss, ataxia, and pyramidal signs. Here we describe an atypical case of infratentorial SS evolving with acute intracranial hypertension in the absence of typical chronic signs.

\section{Introduction}

Superficial siderosis (SS) of the nervous system is an uncommon acquired condition related to hemosiderin deposits in subpial layers of the brain, brainstem, cerebellum, cranial nerves, especially the second and eighth, and spinal cord. The deposits lead to iron-mediated

$\begin{array}{ll} & \text { Maria Sheila Guimarães Rocha } \\ \text { Department of Neurology, Hospital Santa Marcelina } & \text { Rua Santa Marcelina } 177 \\ & \text { São Paulo 08270-070 (Brazil) } \\ \text { msrocha@uol.com.br }\end{array}$




\section{Case Reports in Neurology}

Case Rep Neurol 2021;13:9-16

DOI: $10.1159 / 000510847$

(c) 2021 The Author(s). Published by S. Karger AG, Basel www.karger.com/crn

Guimarães Rocha et al.: Unusual Presentation in Infratentorial Superficial Siderosis: Acute Intracranial Hypertension

neurodegeneration, producing a progressive white matter, and neuronal damage [1]. In the first report in the literature, SS was defined as "melanosis of the brain, cord, and meninges" due to the finding of extended, pigmented, heavy granulations on the spinal cord's ependymal surfaces, cerebellum, and base of the cerebrum in an autopsied case [2]. Hemosiderin deposits probably occur as a consequence of silent, subtle, enduring, or repetitive subarachnoid blood leakage [1].

According to the localization of iron deposition in the brain, two distinct groups of clinicalradiological presentations are recognizable: cortical SS (cSS) and infratentorial SS (iSS) [1, 3]. cSS is restricted to the brain's supratentorial structures, particularly the convexities of the cerebral hemispheres [4]. Depending on the iron involvement extension, cSS may be classified as focal, where no more than three sulci are affected, or disseminated, in case of four or more sulci being involved [5]. Possible etiologies of cSS include prior or recent head trauma and non-traumatic etiologies. Among the non-traumatic causes, we highlight cerebral amyloid angiopathy (CAA), reversible cerebral vasoconstriction syndrome, primary angiitis of the central nervous system (CNS), cortical vein occlusions, posterior reversible leukoencephalopathy syndrome, coagulopathy, drug use, and cavernomas [4, 6-8].

CAA is, by far, the most frequent non-traumatic cause of cSS $[3,9]$. CAA is a cerebrovascular disease characterized by the accumulation of amyloid beta-peptide within the small or medium-sized cerebral blood vessels and leptomeninges [10]. An American population-based study of residents above 50 years of age showed an association of cSS with an increased amyloid burden and apolipoprotein E $\varepsilon 2$ genotype [3]. CAA may cause not only hemorrhagic but also ischemic and inflammatory brain injury [11]. The mechanisms associated with cSS include repeated episodes of acute subarachnoid bleeding from diseased vessels [12], the leakage of a lobar intracerebral hemorrhage, and, eventually, superficial microbleeds into the subarachnoid space [13]. Lastly, it could be due to hemorrhagic transformation of small cortical infarcts [5]. cSS mostly presents with headache, focal or transient focal neurological episodes, as seizures. Cognitive impairment may occur in the disseminated form of cortical siderosis [9].

The diagnosis of iSS should be considered when the siderosis involves the surface of at least two regions out of the following: brainstem, cerebellum, spinal cord, or craniocervical junction [1]. Supratentorial spreading may or not be present. The most typical finding is the presence of siderosis in the crests of cerebellar folia, superior vermis, and vestibulocochlear nerves. However, deposits on the basal cerebral surface, the quadrigeminal plate, and the cord's pial surface may also occur [1,7]. Additionally, SS may be detected in cortical sulci, interhemispheric fissure, or the Sylvian fissure. Possible pathogenetic causes include bleeding from spinal epidural fistulas, arteriovenous malformations, intracranial aneurysms, tumors, and CAA, as mentioned before [1, 8, 14-17].

iSS can be classified into two distinct groups: classical or type 1 iSS, and secondary or type 2 iSS [1]. The classification considers the radiological confirmation of the cause for the CNS bleeding, and subsequently, chronic hemosiderin deposition. Classical type 1 iSS patients do not present any potentially causal confirmed spontaneous or traumatic intracranial bleeding detected through neuroimaging examinations that accounted for SS. Therefore, the bleeding could have raised from microvascular or venous blood low-pressure leakage of the spine or other structures of the posterior fossa, mostly linked to dural abnormalities, previous spinal trauma, or neurosurgery [1].

Conversely, secondary or type 2 iSS assumes the evidence of a potentially causal radiologically confirmed intracranial hemorrhage, well delimited in time, and deemed to be the cause of SS, as traumatic or spontaneous intracranial bleeding event due to subarachnoid

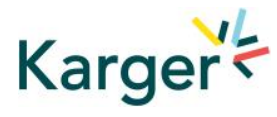




\section{Case Reports in Neurology}

Case Rep Neurol 2021;13:9-16

DOI: $10.1159 / 000510847$

(c) 2021 The Author(s). Published by S. Karger AG, Basel www.karger.com/crn

Guimarães Rocha et al.: Unusual Presentation in Infratentorial Superficial Siderosis: Acute Intracranial Hypertension

hemorrhage, intracerebral hemorrhage, or surgery [1]. The acute bleeding causes a significant blood accumulation, which rapidly deposits in the subpial layers of the CNS near the bleeding site. In this situation, the amount of hemosiderin deposits is proportional to the disease burden. The bleeding episode depicts a different clinical picture, characterized by acute onset of the neurological symptoms and signs. These findings are discordant from those observed in classical iSS, characterized by slowly progressive hearing loss, ataxia, or myelopathy [1].

The diagnostic accuracy depends mostly on the availability of neuroimaging methods. Magnetic resonance imaging (MRI) of the brain and spinal cord are the cornerstones for the diagnosis of SS, especially considering the iron-sensitive sequences used. Besides MRI, other radiological methods should help to locate a possible bleeding source in the nervous system and include computed tomographic angiography, MRI-angiography, brain, and spinal digital subtraction arteriography $[1,9,18]$. In selected cases, surgical exploration must be necessary to unravel the underlying etiology [19]. The appropriately used investigative methods may allow finding the cause of the SS in up to $94 \%$ of patients with classical iSS [1], avoiding the unexplained or "idiopathic" cases of SS reported previously in the literature [4, 20].

The clinical findings in classical iSS may vary according to the affected structures, but the most prevalent features are the slowly progressive onset of sensorineural deafness, cerebellar ataxia, and pyramidal signs, stated as the cardinal signs of this clinical entity [1, 4]. In a systematic review of published cases, Fearnley and colleagues [4] found that sensorineural deafness, progressive ataxia, and pyramidal signs were reported in 95,88 , and $76 \%$ of cases, respectively. Therefore, the most strikingly cardinal feature of SS is hearing impairment, its absence being exceptionally rare. In this series of cases, there was a clear tendency for males to be more often affected than females (3:1). There was a full range for the age of onset of clinical signs, with symptoms occurring both in the teenage years and in the very old. Notably, up to one-third of patients become bed-bound after a decade of disease duration, due to either cerebellar ataxia, progressive myelopathic syndrome, or both [4].

Despite the high prevalence of the cardinal signs of iSS, other neurological manifestations may also be present, including sphincter dysfunction, swallowing deficits, anosmia, seizures, anisocoria, sensory signs, ageusia, and headache [1, 9, 20]. Eventually, memory impairment may occur, leading to dementia [21]. Less common features are extra-ocular motor palsies, neck or backache, bilateral sciatica, and lower motor neuron signs [4]. We draw attention to the fact that chronic intracranial hypertension develops in approximately one-third of cases, either due to hydrocephalus related to the primary etiology or malabsorption of cerebrospinal fluid on damaged arachnoid villi [4]. We report a case of classical iSS presenting with acute intracranial hypertension without any previous iSS cardinal features.

\section{Case Report}

A 31-year-old man was admitted with an 18-day history of a moderate to severe recurrent headache, presenting gradual onset from occipital to bifrontal regions, pulsatile, disabling for routine activities, in episodes lasting beyond $4 \mathrm{~h}$, and progressive worsening. He also related nausea, photo-, and phonophobia in all episodes. Additionally, he presented a history of similar, but less severe, annual headache episodes since adolescence. He had no other comorbidities, apart from mild alcoholism for a decade, being abstinent for 3 years. He denied traumatic brain injury or a previous stroke.

\section{Karger'=}




\section{Case Reports in Neurology}

Case Rep Neurol 2021;13:9-16

DOI: $10.1159 / 000510847$

(c) 2021 The Author(s). Published by S. Karger AG, Basel www.karger.com/crn

Guimarães Rocha et al.: Unusual Presentation in Infratentorial Superficial Siderosis: Acute Intracranial Hypertension

On his first headache day, he received intravenous analgesia at the emergency service, with partial relief of pain. Three days afterward, he returned due to persistent headache and a sudden episode of tonic generalized posture associated with loss of consciousness, lasting less than a minute. On the following days, he disclosed pain alleviation with oral analgesics, but he noticed the appearance of progressively worsening double vision. He was referred to a neurology service by an ophthalmologist.

The neurological examination revealed binocular diplopia, right abducent nerve palsy, and bilateral papilledema. There were no cerebellar or pyramidal tract abnormalities, nor cognitive or behavioral complaints. MRI of the brain showed a diffuse low signal at T1, T2, and GRE, on the infratentorial surfaces, at the level of brainstem, quadrigeminal plate, cerebellum, on the supratentorial at the thalamic surface at lateral ventricles, Sylvian fissure, and paramedian surfaces at frontal and temporal lobes (Fig. 1). Besides, there was mild cerebellar atrophy and enlargement of the fourth ventricle. Additional spinal cord MRI showed similar low signal throughout surfaces, with no other abnormalities (Fig. 2). Cerebral and spinal digital subtraction arteriography resulted in negative findings for vascular or dural abnormalities or any cause for hemosiderin superficial deposition. Routine biochemical and hematological laboratory tests were unremarkable.

A lumbar puncture disclosed cerebrospinal fluid (CSF) opening pressure (OP) of $45 \mathrm{~cm}$ $\mathrm{H}_{2} \mathrm{O}$ and closing pressure of $12 \mathrm{~cm} \mathrm{H}_{2} \mathrm{O}$ after draining $10 \mathrm{~mL}$ in serial tubes. There was significant relief of headache and amelioration of diplopia after CSF drainage. CSF analysis showed no leucocytes or red cells, normal protein, and glucose levels. Pathologic CSF ferritin levels were observed (198 ng/mL; reference value $<12 \mathrm{ng} / \mathrm{mL}$ ), whereas serum ferritin was within normal limits (200 ng/mL; reference value $=21.8-274.6 \mathrm{ng} / \mathrm{mL}$ for men).

Three days after lumbar puncture, there was recrudescent headache and mild diplopia. A new lumbar puncture disclosed $\mathrm{OP}$ of $32 \mathrm{~cm} \mathrm{H}_{2} \mathrm{O}$, with clinical improvement of symptoms after drainage. In the next days, he received pharmacological treatment for intracranial hypertension with progressively increasing dosages of acetazolamide. Despite dose optimization of acetazolamide and associated topiramate, the patient presented recurrence of symptoms with high CSF OP. A lumbar-peritoneal shunt aiming to control intracranial pressure was indicated, but the patient refused, as well treatment with deferiprone. He was discharged after considerable clinical amelioration of both headache and diplopia and in regular use of acetazolamide $(1,500 \mathrm{mg} /$ day $)$ and topiramate $(150 \mathrm{mg} /$ day). Despite the absence of auditive impairment complaint, brain evoked response audiometry was performed and depicted a neurosensorial deficit. The last CSF study disclosed OP of $12 \mathrm{~cm} \mathrm{H}_{2} \mathrm{O}$. Considering the MRI findings of SS and the unremarkable cerebral and spinal angiographic studies, ruling out any source of occult bleeding in the nervous system, the diagnosis of classical iSS was made, despite the absence of canonical cerebellar and pyramidal tract signs and symptoms. The subject has given his written informed consent to publish his case, including publication of images.

\section{Discussion and Conclusion}

The pathophysiology of classical iSS requires the underlying assumption of recurrent subtle, low-volume bleeding in the subarachnoid space. This may be due to various causes, such as lesions secondary to dural abnormalities, as the principal cause, or meningocele, spinal trauma or tumors, arteriovenous malformations, or inflammatory diseases like ankylosing spondylitis $[1,4,7]$. The heme resulting from the breakdown of hemoglobin stimulates

\section{Karger'=}




\section{Case Reports in Neurology}

Case Rep Neurol 2021;13:9-16

DOI: $10.1159 / 000510847$

(c) 2021 The Author(s). Published by S. Karger AG, Basel www.karger.com/crn

Guimarães Rocha et al.: Unusual Presentation in Infratentorial Superficial Siderosis: Acute Intracranial Hypertension

microglia and Bergmann glia to produce hemoxygenase-1, which will break the heme into bilirubin and free iron and ferritin, which will bind to free iron-producing hemosiderin, the most stable compound that will form chronic deposition [22]. Overwhelmed ferritin synthesis leads to the neuronal accumulation of neurotoxic iron and light chain ferritin as a consequence of persistent or recurrent subarachnoid leakage $[1,22,23]$.

The cerebellar convexities and superior cerebellar vermis are particularly affected, presumably due to specific characteristics of CSF flow in this area; thus, the cerebellum and brainstem are irrigated earliest and permanently exposed to bloody CSF, rich in iron and ferritin [23]. Therefore, hemosiderin will deposit manly in the cerebellar folia and the surfaces of the olfactory and vestibulocochlear nerves, defining ataxia and hearing loss as the main symptoms $[1,4]$. The classical clinical signs and symptoms of SS are deemed to be associated with the neurodegeneration in response to hemosiderin deposits in cerebellar and brainstem topography.

The majority of cases evolving with chronic intracranial hypertension are related to secondary SS [4]. The literature review showed only one classical iSS case who presented with an acute crisis of intracranial hypertension [24]. Notably, besides intracranial hypertension syndrome, the patient's neurological examination revealed bilateral hypoacusis and mild cerebellar ataxia of stance and gait, fulfilling the cardinal signs of classical iSS.

In the present case, acute intracranial hypertension presentation was remarkable, disclosing migraine-like cephalalgia and seizure as initial complaints. The whole clinical presentation, including migraine-like cephalalgia, diplopia, papilledema, and abducent nerve palsy, resembled idiopathic intracranial hypertension. Nevertheless, neuroimaging studies ruled out this hypothesis and depicted idiopathic or classical iSS, since no macroscopic changes were observed that could justify chronic subarachnoid bleeding in this case. Surprisingly, there was absence of iSS cardinal symptoms or signs in this patient, despite the remarkable cerebellar, brainstem, and spinal cord hemosiderin deposits. The auditory evoked potential demonstrated subthreshold clinical auditive loss. Accordingly, a period of many years is between the bleeding and the onset of the clinic and radiological signs of SS. Arguably, this patient will sequentially disclose signs and symptoms related to the cerebellar and vestibulocochlear neurodegenerative process that underly SS.

A history of less severe annual headache episodes since adolescence before admission may suggest that the patient had mild and chronic intracranial hypertension secondary to SS and presently discloses an acute episode of intracranial hypertension crisis. The exact mechanism of acute intracranial hypertension crisis is speculative. As far as there was no hydrocephalus in this patient, it is reasonable to state that the crisis might have occurred due to malabsorption of CSF [23] or was eventually associated with cerebral venous hypertension [19]. Feasibly, the recurrent subtle bleeding could be associated with the acute intense inflammatory process in leptomeningeal endothelial cells, which in turn would lead to CSF slowing absorption or eventually, venous hypertension. Indeed, animal experiments with subarachnoid injection of either whole blood, hemolyzed red blood cells, or dextran-iron complex disclosed interesting pathological vascular findings, beyond the neurodegenerative process. There was severe inflammation of the meninges, deposition of iron-positive material in the cells of the ependyma, and also in the macrophages of the meninges. Moreover, iron-positive material was observed in the cuboidal epithelium of the choroid plexus and in the perivascular spaces of the brain tissue, hypothetically leading to CSF malabsorption and hydrocephalus [25]. It is reasonable to presume that the recurrent acute headache episodes, in this case, could be related to a chronic inflammatory process of meninges temporarily aggravated by new

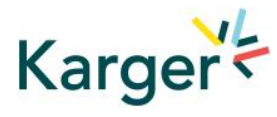




\section{Case Reports in Neurology}

\begin{tabular}{l|l}
\hline Case Rep Neurol 2021:13:9-16 \\
\hline DOI: 10.1159/000510847 & $\begin{array}{l}\text { @ 2021 The Author(s). Published by S. Karger AG, Basel } \\
\text { www.karger.com/crn }\end{array}$ \\
\hline
\end{tabular}

Guimarães Rocha et al:: Unusual Presentation in Infratentorial Superficial Siderosis: Acute Intracranial Hypertension

bleeding, though subtle, but severe enough to provoke additional trouble in an already inadequate CSF absorption.

In conclusion, this case depicts that iSS of the CNS is not only associated with chronic neurological signs and symptoms of iron-associated neurodegeneration. Conversely, it may, in quite rare instances, present as acute intracranial hypertension presenting as the classical syndrome triad of severe headache, nausea and vomiting, and papilledema. The atypical features characterizing this case and other similar published cases must broaden the clinical and pathophysiological spectrum of cerebral SS.

\section{Acknowledgement}

We acknowledge Hospital Santa Marcelina, neurology outpatient clinic, as much as we thank our patient for permitting us to report his clinical data.

\section{Statement of Ethics}

The Institutional Review Board has approved the publication of this case. Written informed consent was obtained from the patient to publish his case, results, and images.

\section{Conflict of Interest Statement}

No potential conflict of interest was reported by the authors.

\section{Funding Sources}

The authors received no specific funding for this work.

\section{Author Contributions}

M.S.G.R and H.S.G.M. developed the original concept of the case report, design, and methodology of the case report. M.S.G.R. drafted the original manuscript. S.M.D.B performed the critical review of the manuscript. R.C., G.M, and A.M.D had full participation in the acquisition and analysis of neuroimaging data. All authors read and approved the final manuscript.

\section{References}

1 Wilson D, Chatterjee F, Farmer SF, Rudge P, McCarron MO, Cowley P, et al. Infratentorial superficial siderosis: Classification, diagnostic criteria, and rational investigation pathway. Ann Neurol. 2017 Mar;81(3):333-43.

2 Hamill RC. Report of a Case of Melanosis of the Brain, Cord and Meninges. J Nerv Ment Dis. 1908;35(9):594. Available from: https://journals.lww.com/jonmd/Fulltext/1908/09000/REPORT_OF_A_CASE_OF_ MELANOSIS_OF_THE_BRAIN,_CORD.27.aspx.

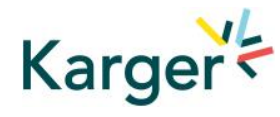




\section{Case Reports in Neurology}

\begin{tabular}{|c|c|}
\hline \multicolumn{2}{|c|}{ Case Rep Neurol 2021;13:9-16 } \\
\hline DOI: 10.1159/000510847 & $\begin{array}{l}\text { (c) } 2021 \text { The Author(s). Published by S. Karger AG, Basel } \\
\text { www.karger.com/crn }\end{array}$ \\
\hline
\end{tabular}

Guimarães Rocha et al.: Unusual Presentation in Infratentorial Superficial Siderosis: Acute Intracranial Hypertension

3 Pichler M, Vemuri P, Rabinstein AA, Aakre J, Flemming KD, Brown RD Jr, et al. Prevalence and Natural History of Superficial Siderosis: A Population-Based Study. Stroke. 2017 Dec;48(12):3210-4.

4 Fearnley JM, Stevens JM, Rudge P. Superficial siderosis of the central nervous system. Brain. 1995 Aug;118(Pt 4):1051-66.

5 Charidimou A, Law R, Werring DJ. Amyloid “spells" trouble. Lancet. 2012 Nov;380(9853):1620.

6 Khurram A, Kleinig T, Leyden J. Clinical associations and causes of convexity subarachnoid hemorrhage. Stroke. 2014 Apr;45(4):1151-3.

7 Kumar N. Superficial siderosis: associations and therapeutic implications. Arch Neurol. 2007 Apr;64(4):4916.

8 Katoh N, Yoshida T, Uehara T, Ito K, Hongo K, Ikeda S. Spinal intradural extramedullary cavernous angioma presenting with superficial siderosis and hydrocephalus: a case report and review of the literature. Intern Med. 2014;53(16):1863-7.

9 Lummel N, Wollenweber FA, Demaerel P, Bochmann K, Malik R, Opherk C, et al. Clinical spectrum, underlying etiologies and radiological characteristics of cortical superficial siderosis. J Neurol. 2015 Jun;262(6):1455-62.

10 Viswanathan A, Greenberg SM. Cerebral amyloid angiopathy in the elderly. Ann Neurol. 2011 Dec;70(6):871-80. Available from: https://pubmed.ncbi.nlm.nih.gov/22190361.

11 Kuhn J, Sharman T. Cerebral Amyloid Angiopathy. In: StatPearls [Internet]. Treasure Island (FL): StatPearls Publishing; 2020.

12 Profice P, Pilato F, Della Marca G, Colosimo C, Gaudino S, Arena V, et al. Recurrent subarachnoid bleeding and superficial siderosis in a patient with histopathologically proven cerebral amyloid angiopathy. Case Rep Neurol. 2011 May;3(2):124-8.

13 Yamada M. Brain hemorrhages in cerebral amyloid angiopathy. Semin Thromb Hemost. 2013 Nov;39(8):955-62.

14 Gaudino S, Colantonio R, Schiarelli C, Martucci M, Calandrelli R, Botto A, et al. Postoperative MR Imaging of Spontaneous Transdural Spinal Cord Herniation: Expected Findings and Complications. AJNR Am J Neuroradiol. 2016 Mar;37(3):558-64.

15 Tosaka M, Sato K, Amanuma M, Higuchi T, Arai M, Aishima K, et al. Superficial siderosis of the central nervous system caused by hemorrhagic intraventricular craniopharyngioma: case report and literature review. Neurol Med Chir (Tokyo). 2015;55(1):89-94.

16 Payabvash S, McKinney AM, Nascene D, Cayci Z. Cerebellar superficial siderosis of chronic subarachnoid hemorrhage in a patient with Tacrolimus-associated posterior reversible encephalopathy. J Postgrad Med. 2014 Oct-Dec;60(4):394-6.

17 Golnari P, Ansari SA, Shaibani A, Hurley MC, Potts MB, Kohler ME, et al. Intradural extramedullary cavernous malformation with extensive superficial siderosis of the neuraxis: case report and review of literature. Surg Neurol Int. 2017 Jun;8(1):109.

18 Stabile A, Di Lazzaro V, Colosimo C, Piazza F, Ferrarese C, DiFrancesco JC. Idiopathic infratentorial superficial siderosis of the central nervous system: case report and review of literature. Neurol Neurochir Pol. 2018 JanFeb;52(1):102-6.

19 Wilden JA, Kumar N, Murali HR, Lindell EP, Davis DH. Unusual neuroimaging in superficial siderosis. Neurology. 2005 Aug;65(3):489.

20 Levy M, Turtzo C, Llinas RH. Superficial siderosis: a case report and review of the literature. Nat Clin Pract Neurol. 2007 Jan;3(1):54-8.

21 Posti JP, Juvela S, Parkkola R, Roine S. Three cases of superficial siderosis of the central nervous system and review of the literature. Acta Neurochir (Wien). 2011 Oct;153(10):2067-73.

22 Koeppen AH, Dentinger MP. Brain hemosiderin and superficial siderosis of the central nervous system. J Neuropathol Exp Neurol. 1988 May;47(3):249-70.

23 Koeppen AH, Michael SC, Li D, Chen Z, Cusack MJ, Gibson WM, et al. The pathology of superficial siderosis of the central nervous system. Acta Neuropathol. 2008 Oct;116(4):371-82.

24 Linder S, Nowak DA, Rodiek SO, Lumenta C, Topka H. Secondary intracranial hypertension with acute intracranial pressure crisis in superficial siderosis. J Clin Neurosci. 2008 Oct;15(10):1168-70.

25 Iwanowski L, Olszewski J. The effects of subarachnoid injections of iron-containing substances on the central nervous system. J Neuropathol Exp Neurol. 1960 Jul;19(3):433-48. 


\section{Case Reports in Neurology}
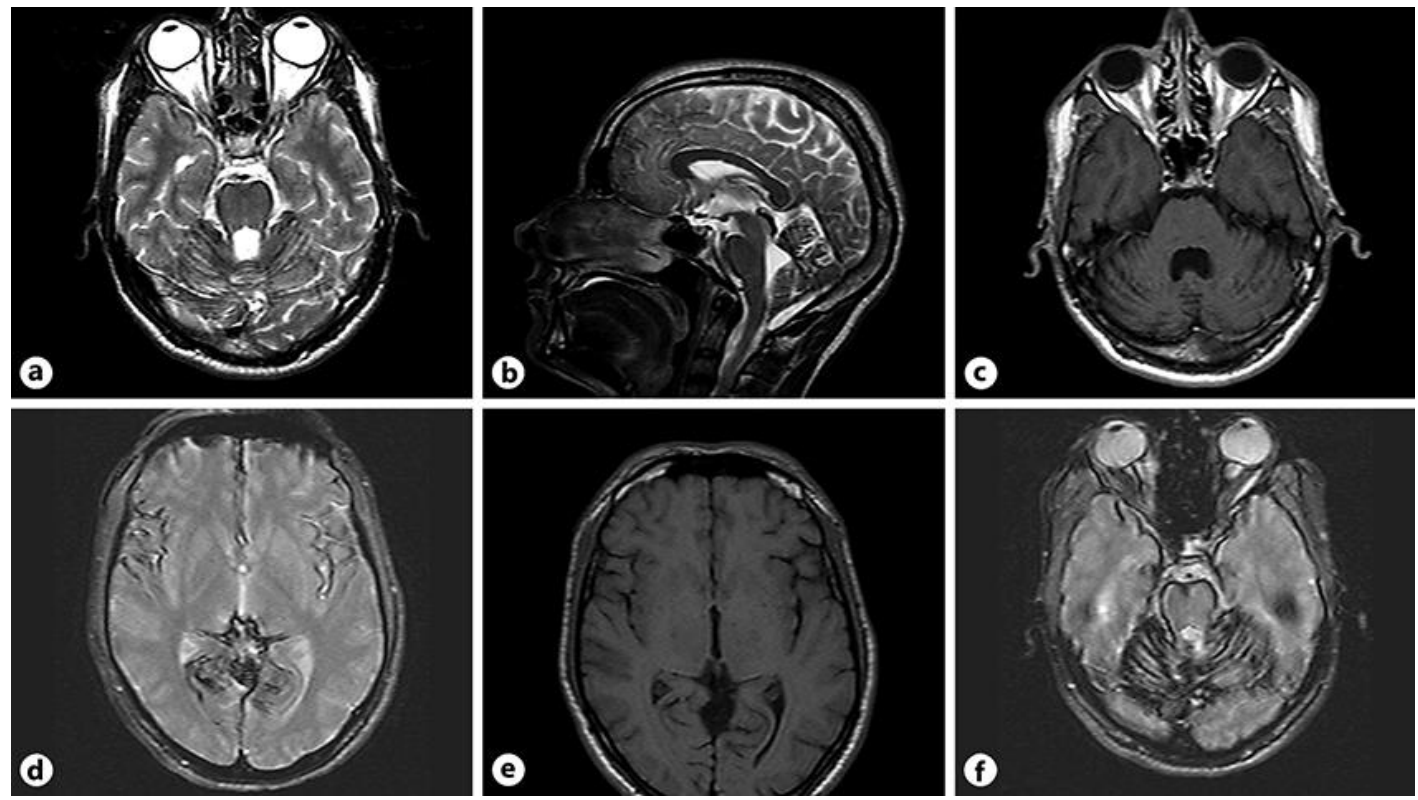

Fig. 1. Brain MRI depicting diffuse low signal at T2, T1, and GRE, on the infratentorial surfaces, at the level of brainstem and cerebellum (a, c, and f), on the supratentorial at the thalamic surface at lateral ventricles, corpus callosum, and quadrigeminal plate (b), and Sylvian fissure and paramedian surfaces at frontal and temporal lobes (d).
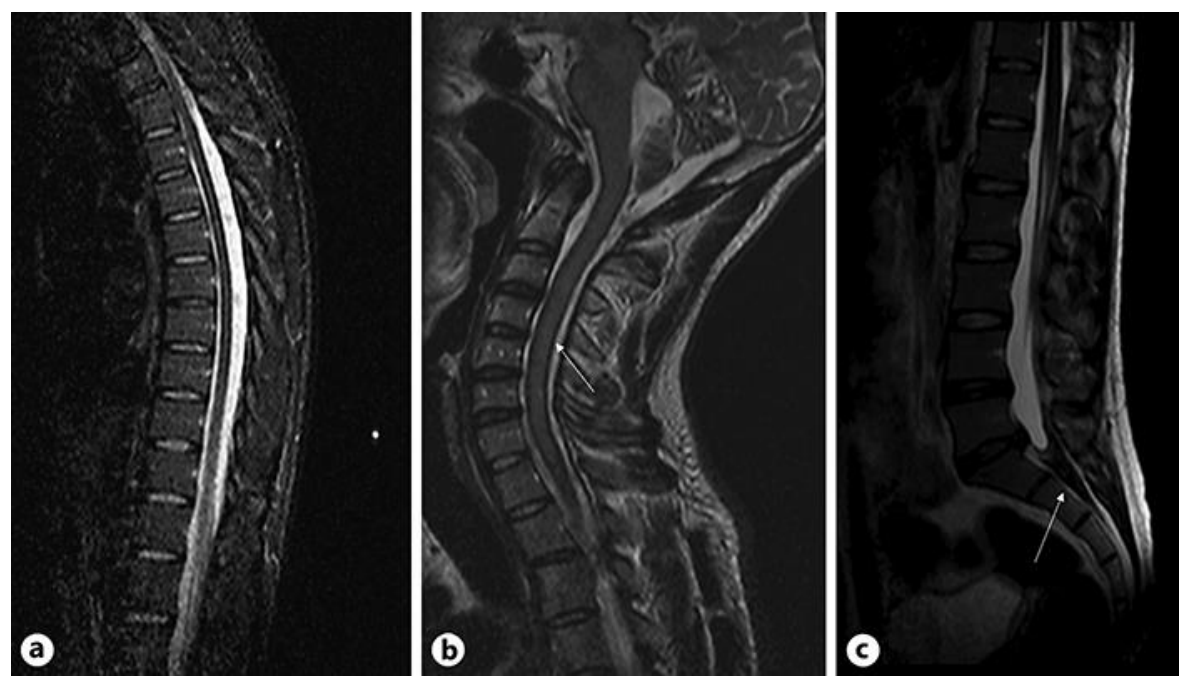

Fig. 2. Sagittal T2 images depicting intense siderosis not only on spinal cord surfaces (a, b) but also in the sacrum (c). 